\title{
PESTICIDES USED IN THAILAND AND TOXIC EFFECTS TO HUMAN HEALTH
}

\author{
Apiwat Tawatsin ${ }^{1}$, Usavadee Thavara ${ }^{1}$, Padet Siriyasatien ${ }^{2}$ \\ ${ }^{1}$ National Institute of Health, Department of Medical Sciences, Ministry of Public Health, \\ Nonthaburi 11000, Thailand \\ ${ }^{2}$ Department of Parasitology, Faculty of Medicine, Chulalongkorn University, Bangkok 10330, \\ Thailand
}

Running Head: PESTICIDES AND HUMAN HEALTH

Correspondence: Padet Siriyasatien; e-mail: padet.s@chula.ac.th

\begin{abstract}
Pesticide intoxication is one of the major public health problems in Thailand and it is caused by intensive use and exposure to pesticides. There was an increasing trend of pesticides imported from about 110,000 tons (14,000 million Baht) in 2007 to approximately 172,000 tons (24,000 million Baht) in 2013. Herbicides were the major pesticides with the highest proportion of import (62 - 79\%) followed by insecticides (12 - 23\%) and fungicides (5 - 11\%). There were about 49,000 to 61,000 reported cases of pesticide intoxication each year with morbidity rate between 76.4 and 96.6 per 100,000 populations. The reported cases of the toxic effects of substances during 2007 - 2013 were found predominantly in the Central region of Thailand (31 $36 \%$ ), followed by the Northeastern region (27 - 31\%), while the annual proportion of the North $(18-20 \%)$ were almost equal to those of the South $(18-19 \%)$. The numbers of cases were usually increased during the growing season of many crops in rainy season (May - August) each year, and it was found mainly in farmers and farm workers. The highest risk was found in patients aged between 45 and 54 years, followed by the groups of 55 - 64 years and $35-44$ years, while the poison risk in men was greater than women. Most of the pesticides identified from patients were organophosphates, carbamates and herbicides, whereas approximately 85 $90 \%$ of total cases could not be identified the causing pesticides. In conclusion, a large amount of pesticides have been annually imported into Thailand and the intensive use of pesticides certainly has consequences for human health and environments even though identifying the true extent of these is quite difficult. To reduce the intensive use of pesticides, it is an urgent need to promote the organic farming practices and search for the effective biopesticides or biological agents to control agricultural pests in order to replace the chemical pesticides.
\end{abstract}

Keyword - pesticides; toxic effects; human health; Thailand 


\section{INTRODUCTION}

The agricultural sector is one of the most important sectors of Thailand economy that has generated food and living incomes for most of the Thai people. Additionally, it has also provided almost constant employment for the majority of Thai labors. Thailand has exported various kinds of agricultural products, such as rice, vegetables, tropical fruits, industrially processed foods and, etc., to many countries around the word.These products accounted for about 9\% of the gross domestic product (GDP) of Thailand in 2009 whereas their production employed $40 \%$ of the workforce and $40 \%$ of the land area [16]. To prevent crop losses to the agricultural pests, pesticides arethen used to control insect and to increase agricultural products [19]. Most of pesticides used in Thailand are imported only. Of the imported pesticides in 2010, about $33 \%$ fall into the WHO hazard categories Ia (extremely hazardous), Ib (highly hazardous) and category II (moderately hazardous) [17]. The need to use hazardous pesticides could raise human health and environmental concerns. Pesticide poisoning is then an important health problem of Thailand as a result of the intensive use of hazardous pesticides. This study intended to explore the pesticides imported into Thailandfrom 2007 to 2013, and the epidemiology of the toxic effects related to pesticide use during that period was revealed and discussed.

\section{MATERIALS AND METHODS}

The information about the quantity of imported pesticides to Thailand and their value (in million Baht) during 2007 - 2013, was obtained via online published annual reports of the Department of Agriculture, Ministry of Agriculture and Co-operative, Thailand [8]. On the other hand, the data of the toxic effects of substances chiefly nonmedicinal as to sourcein Thailand between 2007 and 2013 wasobtained via online published annual reports ofthe Bureau of Policy and Strategy, Ministry of Public Health, Thailand [6]. All data was analyzed and presented as proper figures and tables.

\section{RESULTS AND DISCUSSION}

Farmers in Thailand paid a lot of money for the imported pesticides and it had been increasing from about 14,000 million Baht in 2007 to almost 24,000 million Baht in 2013 (Figure 1). The expense of pesticides used in controlling pests was roughly estimated as about half of the total expense of the crop productions. There were at least 9 groups of the imported pesticides and these include insecticides, fungicides, herbicides, acaricides, rodenticides, plant growth regulator (PGR), mollusicides, fumigants and nematocides. Among these, majority of the money were spent for herbicides $(8,845$ - 14,873 million Baht annually), followed by insecticides (3,686 5,938 million Baht annually) and fungicides (1,833 - 4,828 million Baht annually) (Figure 1). It is, therefore, an urgent need to search the effective biopesticides, such as plant extracts or biological agents to control agricultural pests to replace the chemical pesticides. The organic farming is also an excellent choice to reduce pesticides and fertilizers used in farms while the organic crops have relative high prices in the markets. This will help farmers to save a lot of money and get more profit in return each year and it could also reduce a huge amount of foreign currencies for pesticide import into Thailand. Actually, there is an increasing trend of organic farming in Thailand both local and commercial farms. The certified organic products has been sold in both local super markets in various provinces throughout Thailand, such as Bangkok, Chiang Mai, Khon Kaen, Songkhla, etc., and also exported to some foreign countries with approximately 1.5 - 2 times higher prices than ordinary farming. Regarding health concern, many people are now willing to spend more money to purchase safe vegetables, fruits or local foods. It is obvious that the establishment of organic farming is quite difficult and seems to be expensive at the first start; however, it is, in fact, dramatically cheap as a result of no chemical pesticides and fertilizers used but it also needs more labor care in farms. Until now, the numbers of organic farming 


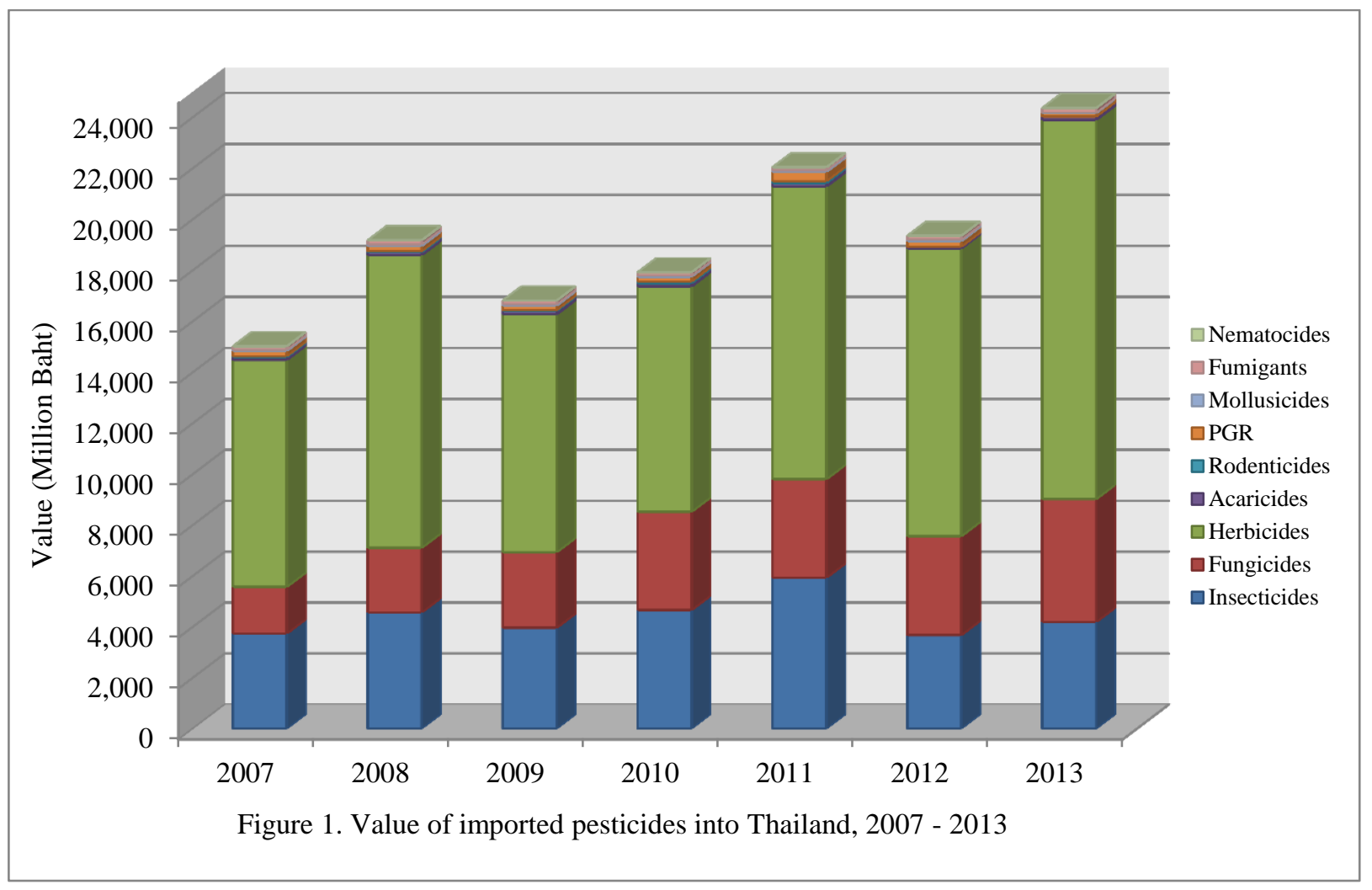

Obviously, there was an increasing trend of pesticides imported from about 110,000 tons totally in 2007 to approximately 172,000 tons totally in 2013 (Figure 2). On this basis, it is estimated that Thailand would import more than 200,000 tons of pesticides annually in the near future. Among these, herbicides were the major pesticides with the highest proportion of import $(68,824$ $137,048$ tons annually, or $62-79 \%)$ followed by insecticides (16,796 - 34,672 tons annually, or $12-23 \%$ ) and fungicides $(6,971-12,178$ tons annually, or $5-11 \%)$, respectively (Figure 2). On the other hand, each of those of acaricides, rodenticides, plant growth regulator (PGR), mollusicides, fumigants and nematocides remains below $2 \%$ annually during that period. The increase of pesticide use in Thailand particularly intends to control pests in farms in order to increase the agricultural productions. In fact, Thailand was ranked third out of 15 Asian countries in pesticide use per unit area and fourth in annual pesticide use [23] whereas the agricultural products per unit area of Thailand were relative low as compared with other countries, probably tenth out of the 15 Asian countries. Regarding health issues, the incidence of acute pesticide poisoning among agricultural workers in Thailand was ranked first out of the 4 Asian countries (Indonesia, Malaysia, Srilanka and Thailand) [13]. Until recently, over three hundred different active ingredients have been registered in Thailand in 2015 with 8,112 formulations for use in agriculture to control pests [9]. All these formulated chemicals have different properties and are meant for specific purposes to control various agricultural pests. 


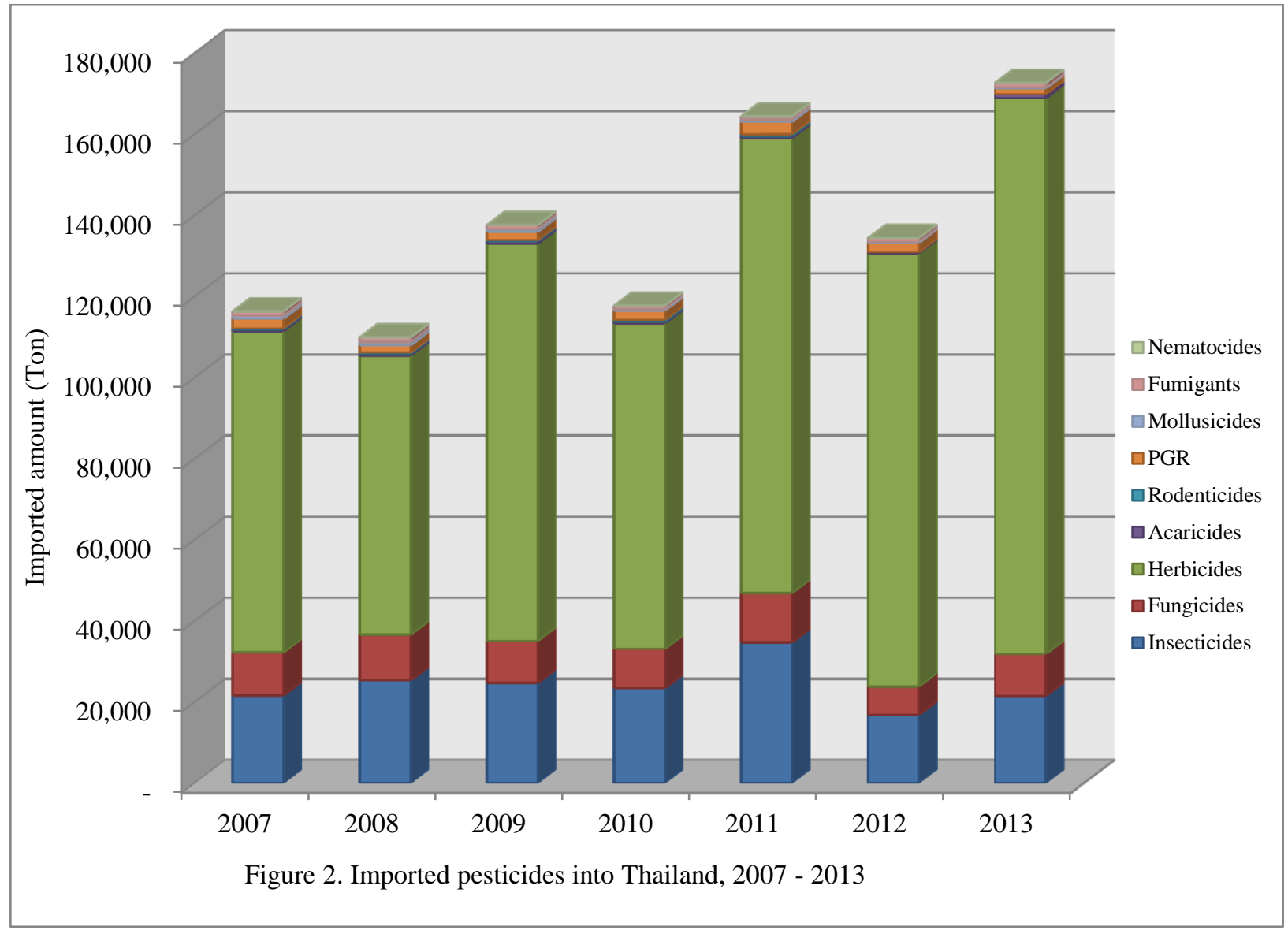

The top ten imported herbicides, insecticides and fungicides by active ingredient (a.i.) into Thailand in 2013 are demonstrated in Table 1. Glyphosate isopropylammonium and paraquat dichloride were the most intensive used herbicides with 27 and 13 million kilogram in 2013, respectively. In fact, both herbicides have been remained for the first and second ranks since previous decade. Other herbicides, such as 2,4-D sodium salt, 2,4-D dimethyl ammonium, ametryn, atrazine, butachlor, diuron and acetochlor were also used heavily in Thailand with over a million kilogram of each one per year. Herbicides are generally used to control weeds in farms and crop lands. They are usually toxic to plants while some are selective for specific target, such as broadleaf weeds. However, herbicide, for example, paraquat is very toxic to human skin and mucous membranes andit is very lethal if patients ingest. It is also suspected that paraquat exposure could be a factor to increase the risk of Parkinson's disease [10]. Additionally, the likelihood 2,4-D herbicides possibly cause cancer in humans [11]. It is also evidence that the exposure to phenoxy herbicides is associated with increased risk of soft tissue sarcoma and non-Hodgkin lymphoma [15]. 
Table 1. Top ten imported herbicides, insecticides and fungicides by active ingredient (a.i.) into Thailand in 2013

\begin{tabular}{|c|c|c|c|c|c|c|}
\hline \multirow{2}{*}{ Rank } & \multicolumn{2}{|l|}{ Herbicides } & \multicolumn{2}{|c|}{ Insecticides } & \multicolumn{2}{|c|}{ Fungicides } \\
\hline & Name & a.i. $(\mathrm{Kg})$ & Name & a.i. $(\mathrm{Kg})$ & Name & a.i. $(\mathrm{Kg})$ \\
\hline 1 & $\begin{array}{l}\text { glyphosate } \\
\text { isopropylammonium }\end{array}$ & $27,994,397$ & chlorpyrifos & $1,193,302$ & mancozeb & $1,513,307$ \\
\hline 2 & paraquat dichloride & $13,823,092$ & cartap hydrochloride & 663,197 & carbendazim & 644,246 \\
\hline 3 & 2,4-D sodium salt & $6,361,633$ & carbaryl & 592,587 & propineb & 548,961 \\
\hline 4 & 2,4-D dimethyl ammonium & $6,121,701$ & cypermethrin & 504,931 & captan & 472,197 \\
\hline 5 & ametryn & $4,621,614$ & carbosulfan & 432,191 & copper hydroxide & 459,518 \\
\hline 6 & atrazine & $4,284,683$ & isoprocarb & 382,785 & propiconazole & 354,286 \\
\hline 7 & butachlor & $2,368,861$ & dichlorvos & 320,994 & difenoconazole & 347,803 \\
\hline 8 & diuron & $1,776,238$ & $\begin{array}{l}\text { chlorpyrifos+ } \\
\text { cypermethrin }\end{array}$ & 263,009 & phosphonic acid & 245,669 \\
\hline 9 & acetochlor & $1,164,241$ & fenobucarb & 215,289 & fosetyl-aluminium & 233,929 \\
\hline 10 & propanil & 987,142 & profenofos & 189,467 & metalaxyl & 152,848 \\
\hline
\end{tabular}

Chlorpyrifos, on the other hand, was the primary insecticide imported to Thailand (more than a million kilogram per year), while those of cartap hydrochloride, carbaryl, cypermethrin and carbosulfan were about half a million kilogram for each one (Table 1). Insecticides are usually used to kill insects that feed on crops and agricultural products. However, pest resurgence and insecticide resistance have been also increased over the time as a result of the intensive use of insecticides. The epidemics of brown planthopper in rice production in Thailand and Asia are the obvious examples of insecticide resistance in agricultural pests [14]. The common used insecticides, such as those in the group of organophosphates and carbamates inhibit acetlycholinesterase activity therefore affect both the central nervous system and the peripheral nervous system and they particularly affect the muscles, glands and smooth muscles that make the body organs function [1, 24]. As for the fungicides, mancozeb was the predominant chemical used to control fungus diseases on plants with approximately 1.5 million kilogram of import to Thailand in 2013, while carbendazim, propineb, captan and copper hydroxide were about half a million kilogram for each one (Table 1).

The incidence of toxic effects of substances chiefly non-medicinal as to source in Thailand between 2007 and 2013 is shown in Figure 3. There were about 49,000 to 61,000 reported cases each year with morbidity rate between 76.4 and 96.6 per 100,000 populations. These included all patients admitted in hospital received toxic substances including pesticides, solvents, corrosives, metals, gases and food; however, the majority belonged to pesticide exposures. It was previously found that 
almost half of the total cases and threefourths of the deaths associated with pesticide poisoning related to agricultural activities [20]. As can be seen, the incidence was slightly declined over the period (Figure 3) whereas the pesticide import was likely increased (Figure 2). It is then suspected that many poisoning cases were never reported to the responsible health agencies and then did not appear in statistics. This would be true because the reported cases were the patients with severe symptoms only while those who had mild symptoms usually refused to access to the hospitals as a result of the financial issues. It is much more difficult to assess the significance of the small doses that contaminate workers daily over long periods, because they usually do not cause clearly defined clinical symptoms. In 2011, the Bureau of Occupational and Environmental Diseases examined blood among 533,524 Thai healthy farmers associated with pesticide applications in 74 provinces of Thailand in order to investigate the toxic effects of pesticide use and it was found that $32 \%$ were in the high risk level [12]. This may imply a burden issue of the toxic effects of pesticides to human health in the long run. The World Health Organization estimated that worldwide exposure to pesticides results in three million cases of acute and chronic poisoning, 750,000 new cases of disease, and 20,000 deaths each year [25]. Three are four potential pathways of pesticide exposures among farmers and farm workers in Thailand and these include (1) take-home pesticides as a result of pesticide residues accumulated on clothing, skin and boots after working in the field, (2) ingestion from food intake containing pesticide residues in foods, (3) environmental causes resulting from pesticide spray or spray drift, and (4) the farmers' unsafe methods of mixing, loading and applying the pesticides [18]. Recently, toxic residues of the insecticides in the group of organophosphate and carbamate were found in indigenous vegetables (Phakkayang and Yanang) and edible insects (cricket and grasshopper) at relatively high proportion $(70-90 \%)$ of the tested samples [7]. This may reflect a high chance to receive pesticide residues via consumption of local foods of Thai people.

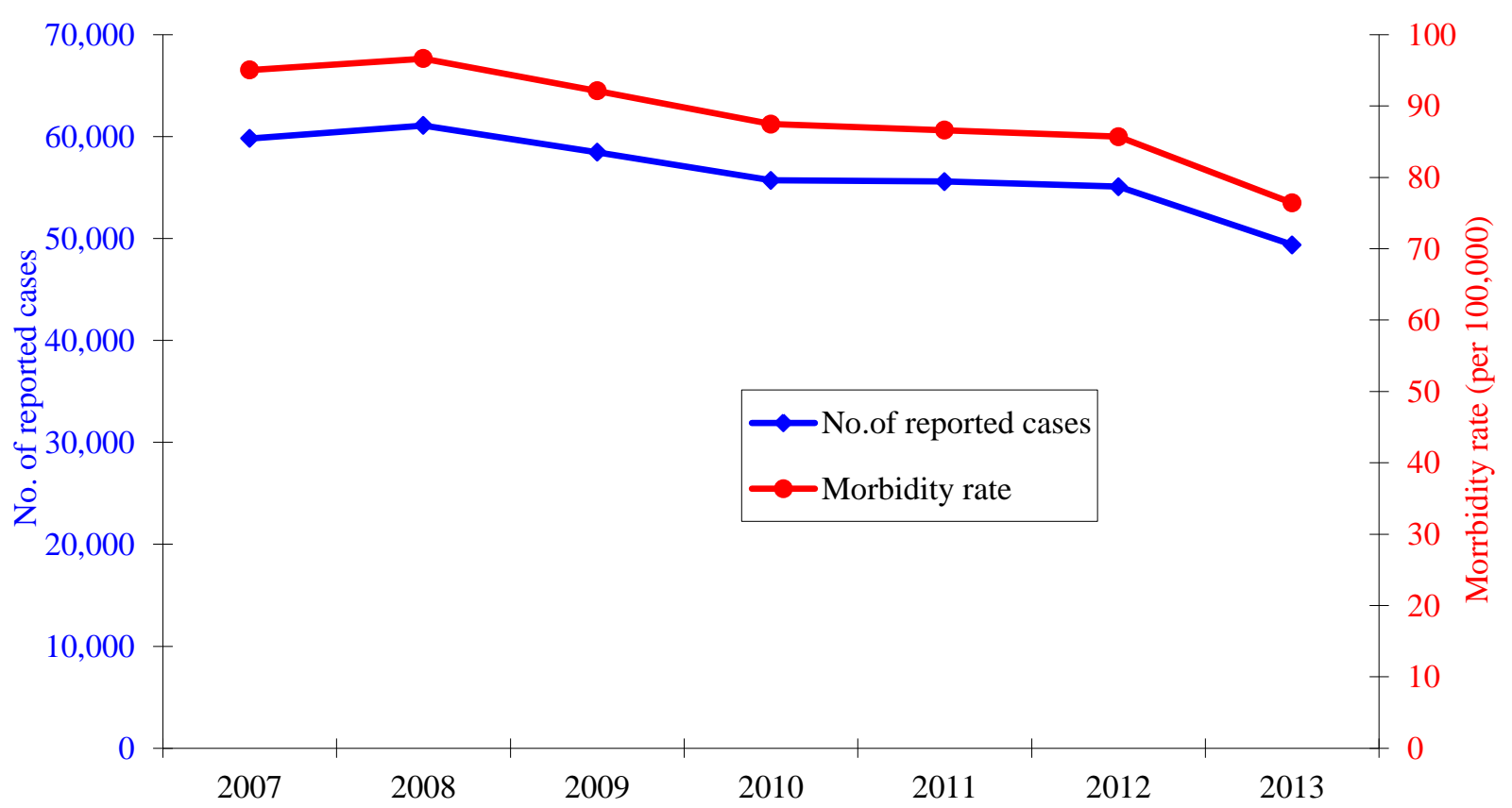

Figure 3. No. of reported cases and morbidity rate (per 100,000 population) of the toxic effects of substances chiefly non-medicinal as to source in Thailand, 2007 - 2013.

The typical symptoms of acute pesticide poisoning are fatigue, headache,skin irritation, skin rash, dizziness, nausea, vomiting, sweating, poor vision, tremors,cramps, coma and subsequently deathin the severe cases [1]. The diagnosis 
of acute pesticide poisoning would be made when one or more of these symptoms, occurring after contact with pesticides. However, these symptoms could also be attributed to other diseases. In fact, the certain diagnosis would be easy and correct if the pesticide residue responsible for the symptoms is detected from the clinical samples, such as stomach content, blood, or urine. On the other hand, pesticides could also cause chronic illnesses if they are incorporated over a long period even though the amounts taken up are relatively small. Symptoms are frequently discursive or do not become apparent for years, which leads to late toxic effects eventually.

The reported cases of the toxic effects of substances during 2007 - 2013 were found predominantly in the Central region of Thailand with about 15,262 - 22,035 cases each year (31 - 36\% of the total cases), followed by the Northeastern region (27 $31 \%$ ), while the annual proportion of the North (18-20\%) were almost equal to those of the South (18 - 19\%) (Figure 4). These geographical differences could possiblybe as a result of the different crop productions and their pesticides used. The primary crops in the Central region of Thailand are rice and various kinds of vegetables (cabbage, onion, chilli, parsley, basil, mint, etc.) and fruits (mango, durian, grape, banana, corn, etc.), while those of the Northeastern region are rice, cassava, corn and sugar cane. The main crops of the Northern region are rice and fruits (longan, orange, lychee), whereas those of the Southern region are rubber, oil palm and fruits (rambutan, mangosteen, coconut). It is likely that the intensive pesticide applications have been applied to control pests in rice, vegetables and fruits.

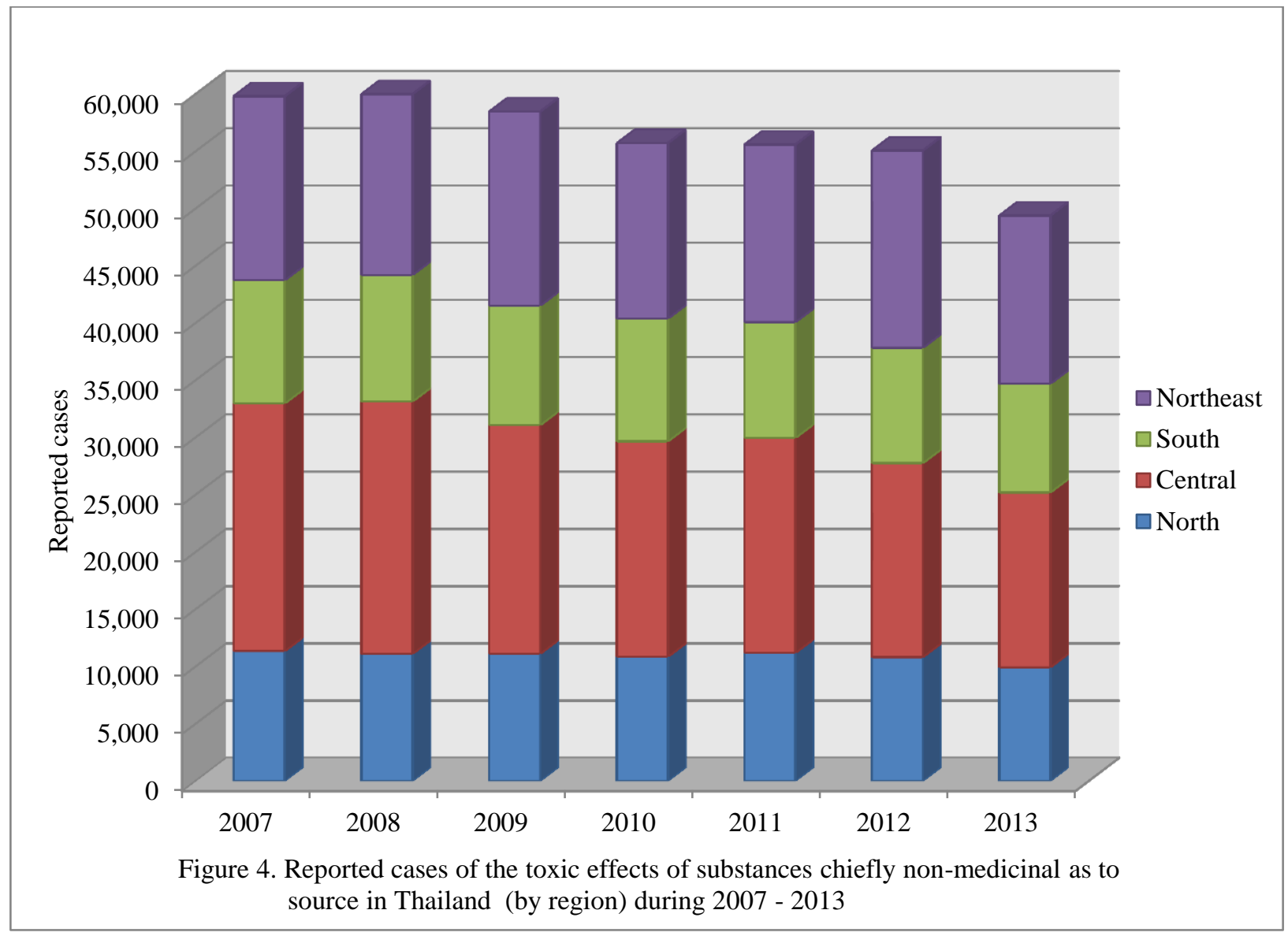

Actually, the numbers of reported cases of pesticide poisoning were usually increased during the growing season of many crops, especially rice in rainy season between May and August each year [22]. It has been found primarily in farmers and farm workers; however, it is also generally affected to other peopleas a result 
ofcontaminated food or consumer goods or pesticide drift from fields. During the growing season, farmers and farm workers usually works in the field for about $8-10$ hours a day, with pesticide applications for 3 - 8 days each month [18]. In addition, there are some implications that Thai farmers are not aware of pesticide hazards, while about half of them apply higher than recommended concentrations, wear no personal protective equipment, and do not observe recommended intervals between spraying and harvest [21]. These clearly indicate a highly potential risk of pesticide exposure among farmers and farm workers in Thailand. The highest risk was found in the patients with ages between 45 and 54 years, followed by the groups of $55-64$ years and $35-44$ years, while the poison risk in men was greater than women, with a ratio varying between 1.16: 1 and 2.0: 1 [25]. It is interesting to note that farmers and farm workers aged 45 - 54 years are the main labor force in the agricultural sector of Thailand, probably account for almost half of the total and they have been exposed to pesticides quite long period for $20-30$ years, usually without proper personal protection when apply pesticides. Therefore, this is the highest risk group for pesticide poisoning in terms of acute and cumulative effects as compared with other age groups having smaller proportions of labor force in the sector. Most of the pesticides identified from patients were organophosphates, carbamates and herbicides, whereas approximately $85-90 \%$ of total cases could not be identified the causing pesticides $[2,4$, 5]. The obvious proof will be approaching if a sufficiently high concentration of the pesticide residue is detected, then it is reasonable to suspect that it might be responsible for the symptoms. The appropriate analytical methods are required to solve this problem. Therefore, some more laboratories have to develop and use the advanced, sensitive and selective techniques, such as liquid chromatographymass spectrometry (LC-MS) and gas chromatography-mass spectrometry (GCMS) to detect the low amount of pesticide residues.
In conclusion, a large amount of pesticides have been annually imported into Thailand and the intensive use of pesticides certainly has consequences for human health and environmentseven though identifying the true extent of these is quite difficult. It is suspected that the current pesticide poisoning in Thailand is now underreporting and the chronic toxic effects related to pesticides are likely considerable. To reduce the intensive use of pesticides, it is an urgent need to promote the organic farming practices and search for the effective biopesticides or biological agents to control agricultural pests in order to replace the chemical pesticides.

\section{CONFLICT OF INTEREST}

None of the authors has any conflict of interest to disclose.

\section{ACKNOWLEDGEMENTS}

We would like to thank Patcharawan Sirisopa for her assistance to gather relevant data and information. 


\section{REFERENCES}

[1] Alavanja M, Hoppin J, Kamel F. 2004. Health effects of chronic pesticide exposure -

cancer andneurotoxicity. Annu Rev

Public Health, 25: 155-197.

[2] Bureau of Epidemiology,

Department of Disease Control, Ministry of

Public

Health. 2010. Annual

Epidemiological Surveillance Report 2010.

[online] Available:

http://www.boe.moph.go.th/Annual/

aesr2553/Open.html

[3] Bureau of Epidemiology,

Department of Disease Control, Ministry of

Public

Health. 2011. Annual

Epidemiological Surveillance Report 2011.

[online] Available:

http://www.boe.moph.go.th/Annual/

AESR2011/index.html

[4] Bureau of Epidemiology,

Department of Disease Control, Ministry of

Public

Health. 2012. Annual

Epidemiological Surveillance Report 2012.

[online] Available:

http://www.boe.moph.go.th/Annual/

AESR2012/index.html

[5] Bureau of Epidemiology,

Department of Disease Control, Ministry of

Public

Health. 2013.Annual

Epidemiological Surveillance Report 2013, [online] Available:

http://www.boe.moph.go.th/Annual/

AESR2013/annual/Pesticides.pdf

[6] Bureau of Policy and Strategy,

Ministry of Public Health. 2015. [online]

Available:

http://bps.ops.moph.go.th/Healthinformatio

n/index.htm

[7] Chaigarun S, Somboon S, Wanchana

S. 2013. Insecticide residues in Isan

vegetable and

local foods. KKU Journal for Public

Health research, 6: 122-129.

[8] Department of Agriculture, Ministry of Agriculture and Co-operative. 2015.

[online]
Available:

http://www.doa.go.th/ard/index.php? option=com_content\&view= article\&id22: stat $2535 \&$ catid=29:stat \&Itemid $=104$

[9] Department of Agriculture, Ministry of Agriculture and Co-operative. 2015. [online]

Available:

http://www.doa.go.th/ard/index.php?option

$=$ com_content $\&$ view $=$ article $\&$ id

$=18$ :news $2 \&$ catid=11:news\&Itemid

$=64$

[10] Dinis-Oliveira RJ, Remiao F, Carmo

H, Duarte JA. Navarro AS, Bastos ML,

Carvalho F.

2006. Paraquat exposure as an etiological factor of Parkinson's

disease. Neuro

Toxicology, 27: 1110-1122.

[11] Ibrahim MA, Bond GG, Burke TA, Cole P, Dost FN, Enterline PE, Gough M, Greenberg

RS, Halperin WE, McConnell E et al. 1991. Weight of the evidence on the human

carcinogenicity of 2,4-D. Environ

Health Perspect, 96: 213-222.

[12] Issarapan P. 2013. Pesticide

poisoning risk among Thai farmers.

[online] Available:

http://www.envocc.org/Budget56/Ec oncouncilVer2.pdf

[13] Jeyaratnam J, Lun KC, Phoon WO.

1987. Survey of acute pesticide poisoning among

agricultural workers in the four

Asian countries. Bulletin of the

World Health Organization, 65: 521-527.

[14] Matsumura M, Takauchi H, Satoh M, Sanada-Morimura S, Otuka A, Watanabe $\mathrm{T}$,

Thanh DV. 2009. Current status of insecticide resistance in rice planthoppers in Asia.

In: Planthoppers: new threats to the sustainability of intensive rice production system in

Asia. Los Banos, Phillippines. 
[15] Morrison HI, Wilkins K, Semenciw R, Mao Y, Wigle D. 1992. Herbicides and cancer.

\section{Journal ofthe National Cancer}

Institute, 84: 1866-1874.

[16] Office of Agricultural Economics

(OAE). 2010. Indicators of agricultural economics of

Thailand 2009. [online] Available:

http://www.oae.go.th

[17] Panuwet P, Siripong W,

Prapamontol T, Ryan PR, Fledler N,

Robson MG, Barr DB.

2012. Agricultural pesticide

management in Thailand: situation and

population health

risk. Environ Sci Policy, 17: 72-81.

[18] Raksanam B, Taneepanichskul S,

Siriwong W, Robson MG. 2012. Factors

associated

with pesticide risk behaviors among

rice farmers in rural community, Thailand.

J Environ EarthSci, 2: 32-39.

[19] Salem H, Olajos EJ. 1988. Review of pesticides: chemistry, uses and toxicology. Toxicology

andIndustrial Health 4: 291-321.

[20] Saoraya J, Inboriboon PC. 2013.

Acute poisoning surveillance in Thailand:

the current

state of affairs and a vision for the

future. ISRN Emergency Medicine, 1-9.

[21] Sinhaseni P. 1994. Toxicological

concepts, regulatory provision and

appropriate

technologyfor pesticide safe use: an

experience in Thailand. Bangkok:

Pesticide Safe Use Unit, Faculty of

Pharmaceutical Sciences,

Chulalongkorn University.

[22] Siripanich S. 2013. Situation and

health effects related to pesticides, 2013.

Weekly

692.

Epidemiological Report 44: 689-

[23] Walter-Echols G, Yangfan P. 2005.

Regional overview and analysis of country reports.

Proceeding of Asia regional workshop on implementation, monitoring and observance international code of conduct on the distribution and use of pesticides.

Bangkok: FAO Regional Office for Asia and the Pacific.

[24] Weisenburger DD. 1993. Human health effects of agrichemical use. Human pathology,

$$
\text { 24: 1383-1386. }
$$

[25] World Health Organization (WHO). 1990. Public health impacts of pesticides used in agriculture. Geneva: WHO. 